\title{
Oculoleptomeningeal Amyloidosis associated with transthyretin Leu12Pro in an African patient
}

\author{
P. McColgan $\cdot$ S. Viegas $\cdot$ S. Gandhi $\cdot$ K. Bull $\cdot$ R. Tudor $\cdot$ F. Sheikh $\cdot$ J. Pinney $\cdot$ M. Fontana $\cdot$ \\ D. Rowczenio · J. D. Gillmore · J. A. Gilbertson - C. J. Whelan - S. Shah · Z. Jaunmuktane \\ J. L. Holton · J. M. Schott $\cdot$ D. J. Werring $\cdot$ P. N. Hawkins $\cdot$ M. M. Reilly
}

Received: 4 October 2014/Revised: 18 November 2014/ Accepted: 20 November 2014/Published online: 9 December 2014

(C) The Author(s) 2014. This article is published with open access at Springerlink.com

\begin{abstract}
Oculoleptomeningeal amyloidosis is a rare manifestation of hereditary transthyretin (TTR) amyloidosis. Here, we present the first case of leptomeningeal amyloidosis associated with the TTR variant Leu12Pro mutation in an African patient. A 43-year-old right-handed Nigerian man was referred to our centre with rapidly progressive neurological decline. He presented initially with weight loss, confusion, fatigue, and urinary and erectile dysfunction. He then suffered recurrent episodes of slurred speech with rightsided weakness. He went on to develop hearing difficulties and painless paraesthesia. Neurological examination revealed horizontal gaze-evoked nystagmus, brisk jaw jerk, increased tone, brisk reflexes throughout and bilateral heelshin ataxia. Magnetic resonance imaging showed extensive leptomeningeal enhancement. Cerebrospinal fluid analysis showed a raised protein of $6.4 \mathrm{~g} / \mathrm{dl}$. Nerve conduction studies showed an axonal neuropathy. Echocardiography was characteristic of cardiac amyloid. TTR gene sequencing
\end{abstract}

P. McColgan $(\bowtie) \cdot S$. Viegas $\cdot$ S. Gandhi $\cdot$ K. Bull

Z. Jaunmuktane - J. L. Holton · J. M. Schott ·

D. J. Werring - M. M. Reilly

MRC Centre for Neuromuscular Diseases, UCL Institute

of Neurology, Queen Square, London WC1N 3BG, UK

e-mail: p.mccolgan@ucl.ac.uk

R. Tudor · F. Sheikh

Cavan General Hospital, Lisdarn, Cavan, Republic of Ireland

J. Pinney $\cdot$ M. Fontana $\cdot$ D. Rowczenio .

J. D. Gillmore · J. A. Gilbertson · C. J. Whelan · P. N. Hawkins

National Amyloidosis Centre, Royal Free Hospital,

Rowland Hill Street, London NW3 2PF, UK

S. Shah

Department of Neuroradiology, National Hospital of Neurology and Neurosurgery, University College London Hospitals,

Queen Square, London WC1N 3BG, UK showed that he was heterozygous for the leucine 12 proline mutation. Meningeal and brain biopsy confirmed widespread amyloid angiopathy. TTR amyloidosis is a rare cause of leptomeningeal enhancement, but should be considered if there is evidence of peripheral or autonomic neuropathy with cardiac or ocular involvement. The relationship between different TTR mutations and clinical phenotype, disease course, and response to treatment remains unclear.

Keywords Genetics · Amyloid · Transthyretin · Leu12Pro

\section{Introduction}

Transthyretin (TTR), a serum precursor protein of amyloid, [1] is predominantly produced in the liver. However, some TTR is also produced in the central nervous system (CNS) within the choroid plexus and the pigmented epithelium of the retina [2]. Many mutations in the transthyretin gene are known to cause familial amyloid polyneuropathy (FAP), an autosomal dominant multisystem disease [3].

OLMA is a rare manifestation of TTR amyloidosis, characterised by amyloid deposition in the meninges of the brain and spinal cord, often with ocular involvement. Patients present with a wide variety of neurological problems including epilepsy [4], subarachnoid haemorrhage [5], hearing or visual loss $[6,7]$ and headache [8]. While many TTR mutations can cause both FAP and OLMA [6, 9, 10], the extremely rare Leu12Pro mutation has only been associated with OLMA to date.

We described the first case of the TTR Leu12Pro mutation in 1999 [8]. To date, the only cases described have been in patients of European ancestry. Here, we present the first case of the TTR Leu12Pro variant in a patient of African origin. 


\section{Case report}

A 43-year-old right-handed Nigerian man was referred to our centre with rapidly progressive neurological decline over a 19-month period. He presented initially in March 2011 with weight loss of $20 \mathrm{~kg}$ over 3 months. Two months later, he developed progressive confusion, fatigue, erectile difficulties, urinary urgency and incontinence. In March 2012, he suffered from recurrent episodes of slurred speech and rightsided weakness, lasting $30 \mathrm{~min}$. At his local hospital, a noncontrast MRI head was normal, but an echocardiogram identified a restrictive cardiomyopathy and he was started on aspirin. The episodes were initially every 2 weeks but increased in frequency over time. In June 2012, he developed new left-sided hearing difficulties. By October 2012, he had developed painless paraesthesia in both feet.

There was no relevant past medical history. His father had suffered from weight loss, erectile dysfunction and renal problems, and died of a myocardial infarction in his 60s. His mother died in her 50s of unknown cause. Of his four siblings, the oldest brother died at age 14 but no clear cause was established. His sister had developed deafness in her 40s.

Cardiovascular, respiratory and abdominal examination was unremarkable. Screening cognitive testing demonstrated anterograde memory difficulties, and impairment of attention and concentration; the MMSE score was 21/30. He had horizontal gaze-evoked nystagmus and a brisk jaw jerk, but cranial nerve examination was otherwise normal. Neuro-ophthalmological assessment was normal. Examination of the limbs revealed increased tone and brisk reflexes in the upper and lower limbs and mild bilateral heel-shin ataxia.

\section{Investigations}

The following blood tests were normal or negative: Full blood count, urea and electrolytes, liver function tests, thyroid function, cardiac enzymes, B12, folate, serum ACE, HIV, HTLV-1, and treponemal serology, ANA, ANCA, anti-neuronal antibodies, serum-free light chain assay, electrophoresis and immunofixation. Urine testing confirmed a normal creatinine clearance and no proteinuria. On the basis of the autonomic symptoms and restrictive cardiomyopathy, sequencing of the TTR gene was performed, revealing that he was heterozygous for the mutation leucine 12 proline.

\section{Neurological investigations}

Magnetic resonance imaging (MRI) of the brain and spine showed extensive leptomeningeal enhancement over the surface of the brain and spinal cord (Fig. 1). No signal change was demonstrated within the underlying parenchyma. Susceptibility-weighted sequences revealed no parenchymal microhaemorrhages, or evidence of subarachnoid blood products. Magnetic resonance angiography of the intra- and extra-cranial arteries was normal. There was also evidence of mild, diffuse thickening of the intrathecal nerve roots, and nerves of the brachial and lumbosacral plexus (Fig. 2).

Cerebrospinal fluid (CSF) analysis showed seven white cells (four lymphocytes and three polymorphs), CSF protein was elevated at $6.4 \mathrm{~g} / \mathrm{dl}$, with a normal glucose ratio (3.6 mmol/l CSF and $5.9 \mathrm{mmol} / \mathrm{l} \mathrm{serum}$ ), oligoclonal bands were not detected. Whilst the CSF Ab1-42 was depressed (371 pg/ml, reference range 627-1,322) possibly reflecting sequestration within CNS amyloid plaques as is seen in Alzheimer's disease (AD), unlike in AD the CSF tau level was also low (107 pg/ml, reference range 146-595) mitigating against an ongoing neurodegenerative process. Two further CSF examinations showed a mild pleocytosis and persistently raised CSF protein. No organisms were cultured (including mycobacterium tuberculosis) and no cellular atypia was seen.

Nerve conduction studies demonstrated a mild large fibre peripheral neuropathy in the lower limbs and a severe small fibre neuropathy affecting both the upper and lower limbs. Autonomic function testing showed a low resting supine blood pressure (BP) of $101 / 65 \mathrm{mmHg}$ and

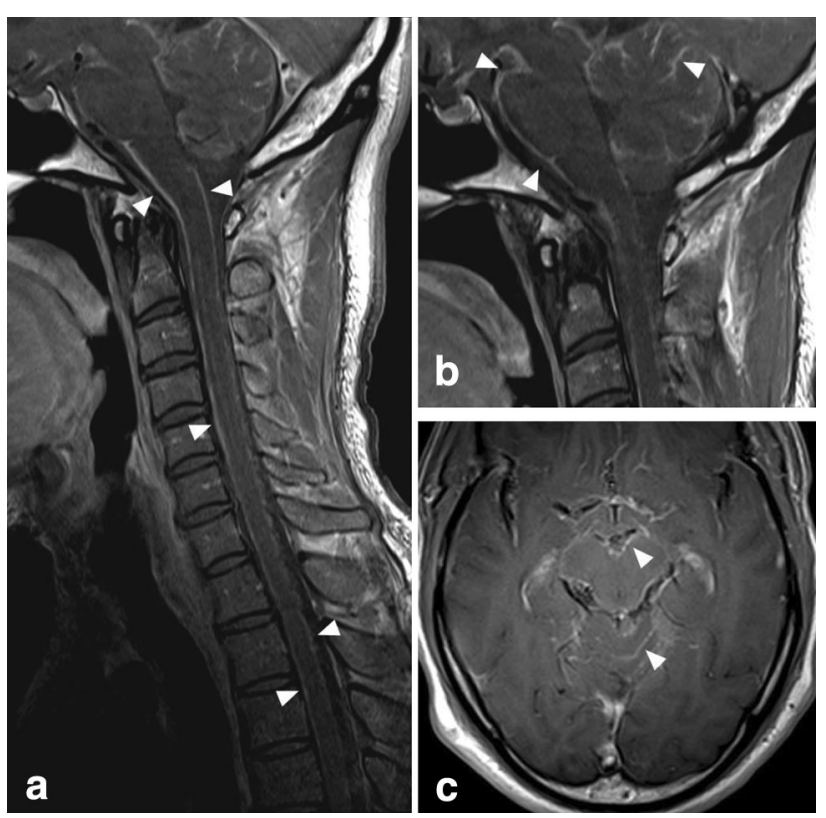

Fig. 1 Post-gadolinium T1-weighted MR images of the cervical spine (a, b) and brain (c), demonstrating diffuse, mildly nodular leptomeningeal enhancement over the surface of the spinal cord, brain stem and cerebellum (arrowheads) 
Fig. 2 Axial T2-weighted MR images of the lumbosacral spine (a, b), demonstrating mild hypertrophy of the spinal nerve roots. Mild prominence of the lumbosacral plexus bilaterally is also shown (arrows). Note the distended urinary bladder with a trabeculated wall (asterisk)
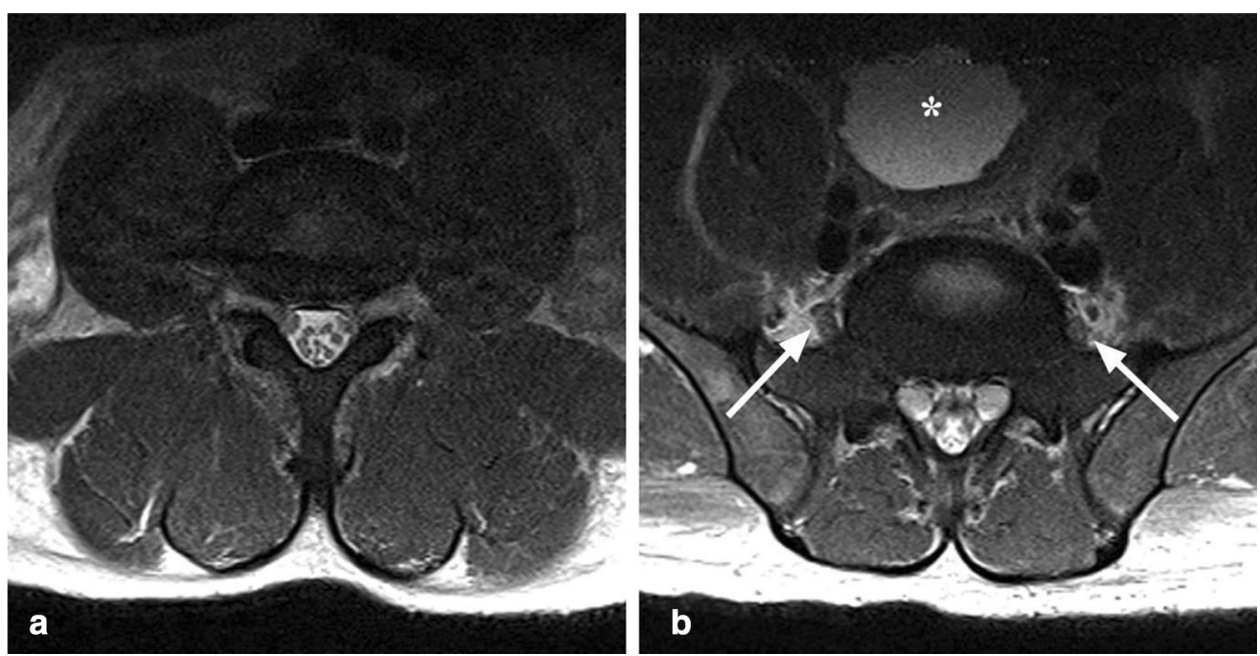

b orthostatic hypotension on standing at $3 \mathrm{~min}$ with BP dropping to $77 / 50 \mathrm{mmHg}$. A 48 -h period of inpatient video telemetry showed mild global cortical dysfunction but no focal features or epileptiform abnormalities.

Neuro-otology investigations confirmed a mixed leftsided peripheral and central vestibular disorder with sparing of the auditory pathway. Neuropsychometry testing showed profoundly impaired processing speed with widespread cognitive impairment reflecting severe subcortical dysfunction.

A brain biopsy was performed to confirm amyloid deposition and exclude any other pathology. The histology confirmed widespread amyloid angiopathy involving dura mater, leptomeninges and neocortical blood vessels as well as occasional vessels in the white matter. There was no evidence of underlying malignancy or vasculitis. (see Fig. 3).

\section{Other investigations}

Serum amyloid $\mathrm{P}$ component scintigraphy demonstrated the modest amyloid deposits in the spleen and kidneys.

ECG revealed sinus rhythm with small complexes in the inferior leads. Echocardiogram demonstrated an ejection fraction of $51 \%$, mild to moderate diastolic dysfunction with elevated filling pressures. Cardiac MRI showed moderate left ventricular (LV) wall thickening and moderate LV systolic dysfunction, along with diffuse biventricular late gadolinium enhancement typical of cardiac amyloidosis. TC-labelled DPD scintigraphy showed grade III localization in the heart, characteristic of cardiac TTR amyloidosis.

Arterial blood gas sampling demonstrated central hypoventilation causing respiratory failure.

\section{Disease course}

During his inpatient stay he continued to deteriorate, remaining very drowsy with fluctuating agitation and confusion. Liver transplantation was considered but excluded due to the lack of evidence for benefiting TTR amyloidosis patients with CNS disease, along with the presence of cardiac amyloidosis and the rapid deterioration of the patient's cognitive function. He was subsequently repatriated to his local hospital. At the time of writing, he has spent 330 days in hospital. There has been a gradual decline in his overall condition. He has developed an atonic bladder, with recurrent urosepsis and now has an indwelling catheter.

\section{Discussion}

OLMA was first described by Goren in 1980 [11], since then 14 TTR mutations causing leptomeningeal amyloidosis have been identified [5, 7, 9-16]. Until now, these have been found exclusively in European, American and Japanese patients. The syndrome remains extremely rare, with only 74 patients reported with OLMA in the literature [4-30]. Age of onset ranges from 28 to 69 years, with a large variation in time from presentation to time of death, ranging from 6 months to 26 years (Table 1). The reported cases of Leu12Pro have presented with a spectrum of cognitive difficulties, ataxia, epilepsy, headache, peripheral neuropathy, autonomic dysfunction, visual and hearing loss. We report here the first case of leptomeningeal amyloidosis in an African patient with the Leu12Pro mutation. This patient presented with episodic symptoms of dysarthria and right-sided weakness, on a background of an autonomic and peripheral neuropathy, and cognitive 


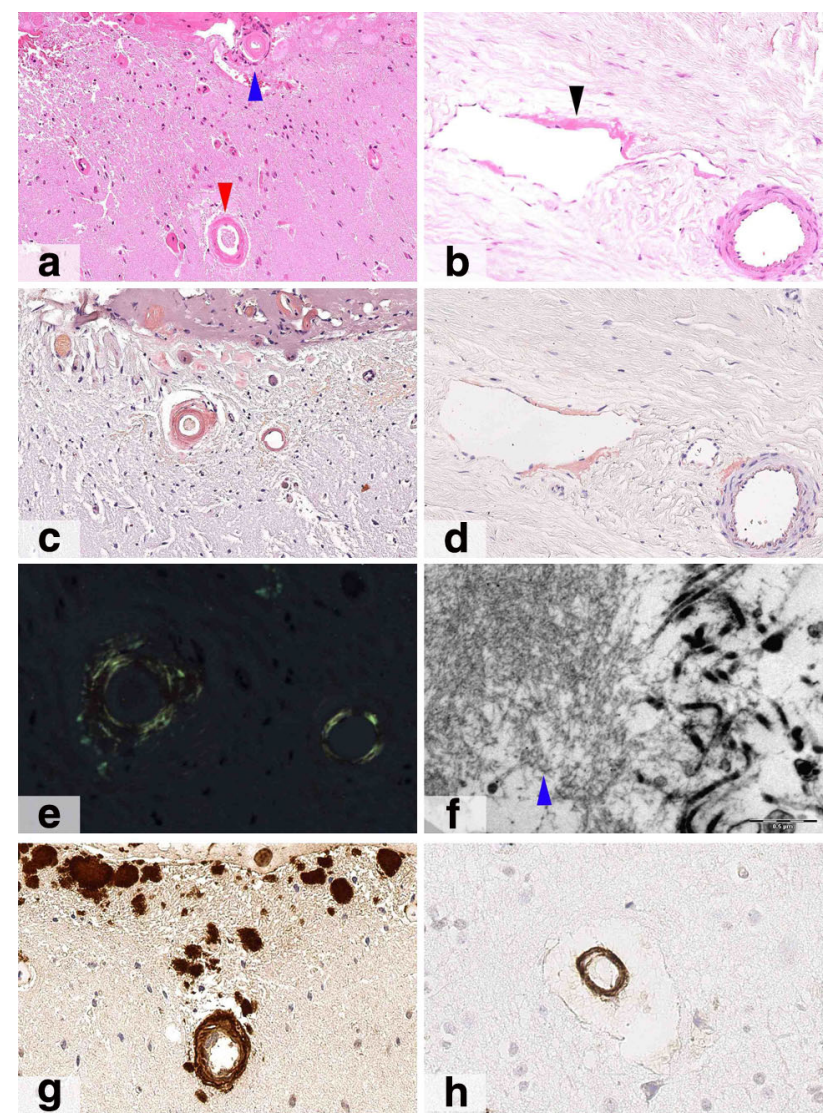

Fig. 3 Brain biopsy of meningeal and cerebral amyloid angiopathy Haematoxylin-Eosin stained sections (a and b) show thickened brightly eosinophilic walls of small vessels in the leptomeninges (blue arrowhead in a), neocortex (red arrowhead in a) and pachymeninges (black arrowhead in b). Affected vessels are positively stained with Congo red (c and $\mathbf{d}$ ) which shows apple green birefringence under polarised light (e). Ultrastructural assessment (f) confirms the presence of haphazardly arranged amyloid fibrils in the dura mater (blue arrowhead). TTR protein $(\mathrm{G})$ is widely deposited in the walls of the blood vessels and in addition shows patchy parenchymal deposits with a subpial distribution. A small proportion of the vessels in brain parenchyma also contain amyloid $\beta$ deposits $(\mathrm{H})$ likely to represent co-localization of entrapped amyloid $\beta$ protein. Scale bar $100 \mu \mathrm{m}$ $(\mathbf{a}-\mathbf{d}) ; 30 \mu \mathrm{m}(\mathbf{e}) ; 0.5 \mu \mathrm{m}(\mathbf{f}) ; 50 \mu \mathrm{m}(\mathbf{g}-\mathbf{h})$

decline. In addition, he also demonstrated pyramidal and cerebellar signs on examination.

Leptomeningeal amyloid was most likely responsible for the transient focal neurological episodes. Convexity SAH and siderosis with TTR mutations has been described [5], and that although we did not find SAH or siderosis, leakage of blood products from amyloid laden fragile leptomeningeal small vessels may have been the underlying substrate for the attacks. Such transient attacks have been described frequently in sporadic cerebral amyloid angiopathy [31].

The contribution of TTR produced in various anatomical sites to the disease-causing CNS amyloid deposits in OLMA remains unclear, i.e. TTR produced locally within the brain versus liver-derived TTR from the systemic circulation. Whilst de novo oculoleptomeningeal amyloid deposition apparently may occur after liver transplantation has been performed in patients with TTR mutations to remove the source of variant TTR in the blood [32], many studies have also confirmed that wild-type TTR can continue to accumulate after liver transplant on the existing template of amyloid associated with variant TTR. A study of a patient who received a domino liver transplant using an explanted FAP Val30Met patient's liver has confirmed that mutant TTR in the plasma does enter the brain [33]. Whilst liver transplantation has been performed in patients with OLMA associated with various TTR mutations, published outcome has varied and its role remains unclear. Survival for patients with TTR Leu12Pro has ranged from 6 months to 3 years [17], while survival at 5 and 6 years was reported with $\mathrm{T} 114 \mathrm{C}$ [21] and $\mathrm{T} 69 \mathrm{H}$ [23] patients, respectively. Yamashita and colleagues also corroborated that patients with $\mathrm{T} 114 \mathrm{C}$ mutation may have a better prognosis following liver transplantation. In a study of 8 patients with the T114C mutation, they found that those receiving liver transplant had reduced mortality and morbidity related to dementia and subarachnoid haemorrhage [34].

The selectivity of Leu12Pro mutations to the central nervous system is postulated to be due to regional differences in cell proteostasis. While unstable mutants, such as Leu12Pro, are subject to degradation by the endoplasmic reticulum in the liver, mutant TTR produced by the choroid plexus binds to thyroxine (T4) causing stabilisation, thereby preventing endoplasmic reticulum degradation. Once the mutant TTR is released in the CSF T4 dissociates causing destabilisation and the formation of TTR aggregates [35].

Although OLMA is a rare condition, it is a devastating and life-threatening disease. Its precise pathogenesis and the mechanism of disease progression, which are remarkably rapid in our case, remain unclear as does the role of liver transplantation. 


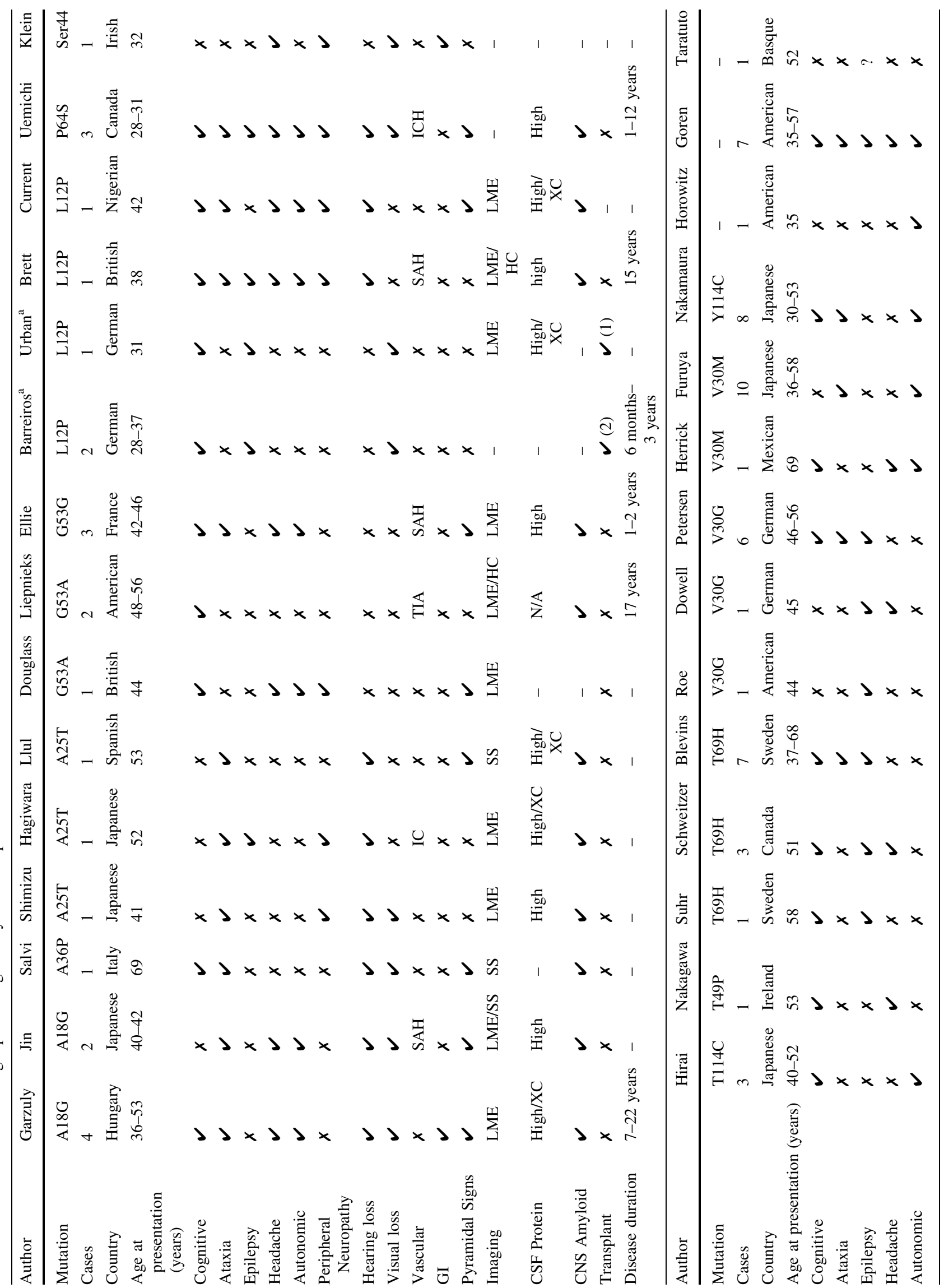




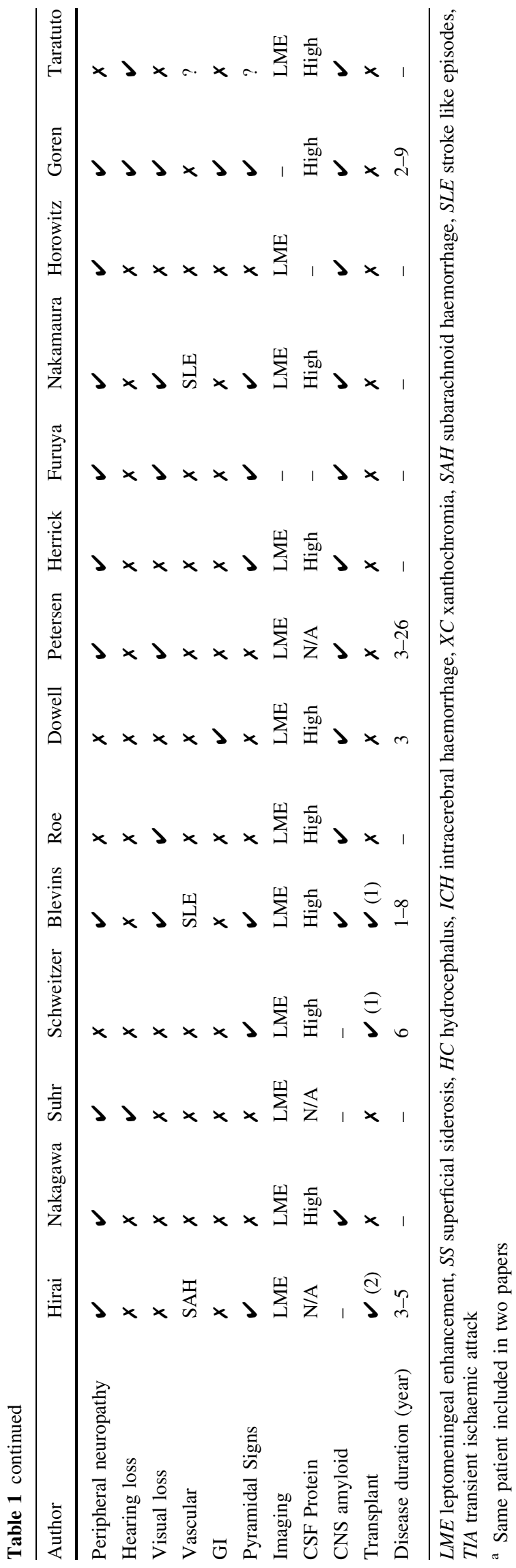

Conflicts of interest On behalf of all authors, the corresponding author states that there is no conflict of interest.

Open Access This article is distributed under the terms of the Creative Commons Attribution License which permits any use, distribution, and reproduction in any medium, provided the original author(s) and the source are credited.

\section{References}

1. Costa PP, Figueira AS, Bravo FR (1978) Amyloid fibril protein related to prealbumin in familial amyloidotic polyneuropathy. Proc Natl Acad Sci USA 75(9):4499-4503

2. Soprano DR, Herbert J, Soprano KJ, Schon EA, Goodman DS (1985) Demonstration of transthyretin mRNA in the brain and other extrahepatic tissues in the rat. J Biol Chem 260(21): 11793-11798

3. Plante-Bordeneuve V, Said G (2011) Familial amyloid polyneuropathy. Lancet Neurol 10(12):1086-1097

4. Suhr OB, Andersen O, Aronsson T, Jonasson J, Kalimo H, Lundahl C et al (2009) Report of five rare or previously unknown amyloidogenic transthyretin mutations disclosed in Sweden. Amyloid Int J Exp Clin Invest Off J Int Soc Amyloid 16(4):208-214

5. Jin K, Sato S, Takahashi T, Nakazaki H, Date Y, Nakazato M et al (2004) Familial leptomeningeal amyloidosis with a transthyretin variant Asp18Gly representing repeated subarachnoid haemorrhages with superficial siderosis. J Neurol Neurosurg Psychiatry 75(10):1463-1466

6. Garzuly F, Vidal R, Wisniewski T, Brittig F, Budka H (1996) Familial meningocerebrovascular amyloidosis, Hungarian type, with mutant transthyretin (TTR Asp18Gly). Neurology 47(6): $1562-1567$

7. Douglass C, Suvarna K, Reilly MM, Hawkins PN, Hadjivassiliou M (2007) A novel amyloidogenic transthyretin variant, Gly53Ala, associated with intermittent headaches and ataxia. J Neurol Neurosurg Psychiatry 78(2):193-195

8. Brett M, Persey MR, Reilly MM, Revesz T, Booth DR, Booth SE et al (1999) Transthyretin Leu12Pro is associated with systemic, neuropathic and leptomeningeal amyloidosis. Brain $\mathbf{J}$ Neurol 122(Pt 2):183-190

9. Nakamura M, Yamashita T, Ueda M, Obayashi K, Sato T, Ikeda $\mathrm{T}$ et al (2005) Neuroradiologic and clinicopathologic features of oculoleptomeningeal type amyloidosis. Neurology 65(7): 1051-1056

10. Herrick MK, DeBruyne K, Horoupian DS, Skare J, Vanefsky MA, Ong T (1996) Massive leptomeningeal amyloidosis associated with a Val30Met transthyretin gene. Neurology 47(4): 988-992

11. Goren H, Steinberg MC, Farboody GH (1980) Familial oculoleptomeningeal amyloidosis. Brain J Neurol 103(3):473-495

12. Salvi F, Pastorelli F, Plasmati R, Bartolomei I, Dall'Osso D, Rapezzi C (2012) Genotypic and phenotypic correlation in an Italian population of hereditary amyloidosis TTR-related (HATTR): clinical and neurophysiological aids to diagnosis and some reflections on misdiagnosis. Amyloid Int J Exp Clin Invest Off J Int Soc Amyloid 19(Suppl 1):58-60

13. Shimizu $Y$, Takeuchi $M$, Matsumura $M$, Tokuda $T$, Iwata $M$ (2006) A case of biopsy-proven leptomeningeal amyloidosis and intravenous Ig-responsive polyneuropathy associated with the Ala25Thr transthyretin gene mutation. Amyloid Int J Exp Clin Invest Off J Int Soc Amyloid 13(1):37-41

14. Hagiwara K, Ochi H, Suzuki S, Shimizu Y, Tokuda T, Murai H et al (2009) Highly selective leptomeningeal amyloidosis with transthyretin variant Ala25Thr. Neurology 72(15):1358-1360 
15. Liepnieks JJ, Dickson DW, Benson MD (2011) A new transthyretin mutation associated with leptomeningeal amyloidosis. Amyloid Int J Exp Clin Invest Off J Int Soc Amyloid 18(Suppl 1): $155-157$

16. Ellie E, Camou F, Vital A, Rummens C, Grateau G, Delpech M et al (2001) Recurrent subarachnoid hemorrhage associated with a new transthyretin variant (Gly53Glu). Neurology 57(1): $135-137$

17. Barreiros AP, Post F, Hoppe-Lotichius M, Linke RP, Vahl CF, Schafers HJ et al (2010) Liver transplantation and combined liver-heart transplantation in patients with familial amyloid polyneuropathy: a single-center experience. Liver Trans Off Publ Am Assoc Study Liver Dis Int Liver Trans Soc 16(3):314-323

18. Urban PP, Hertkorn C, Schattenberg JM, Gawehn J, Hagele S, Wunsch M et al (2006) Leptomeningeal familial amyloidosis: a rare differential diagnosis of leptomeningeal enhancement in MRI. J Neurol 253(9):1238-1240

19. Uemichi T, Uitti RJ, Koeppen AH, Donat JR, Benson MD (1999) Oculoleptomeningeal amyloidosis associated with a new transthyretin variant Ser64. Arch Neurol 56(9):1152-1155

20. Klein CJ, Nakumura M, Jacobson DR, Lacy MQ, Benson MD, Petersen RC (1998) Transthyretin amyloidosis (serine 44) with headache, hearing loss, and peripheral neuropathy. Neurology 51(5): 1462-1464

21. Hirai T, Ando Y, Yamura M, Kitajima M, Hayashida Y, Korogi $\mathrm{Y}$ et al (2005) Transthyretin-related familial amyloid polyneuropathy: evaluation of CSF enhancement on serial T1-weighted and fluid-attenuated inversion recovery images following intravenous contrast administration. AJNR Am J Neuroradiol 26(8):2043-2048

22. Nakagawa K, Sheikh SI, Snuderl M, Frosch MP, Greenberg SM (2008) A new Thr49Pro transthyretin gene mutation associated with leptomeningeal amyloidosis. J Neurol Sci 272(1-2):186-190

23. Schweitzer K, Ehmann D, Garcia R, Alport E (2009) Oculoleptomeningeal amyloidosis in 3 individuals with the transthyretin variant Tyr69His. Can J Ophthalmol J Can D'ophtalmol 44(3):317-319

24. Blevins G, Macaulay R, Harder S, Fladeland D, Yamashita T, Yazaki $M$ et al (2003) Oculoleptomeningeal amyloidosis in a large kindred with a new transthyretin variant Tyr69His. Neurology 60(10):1625-1630
25. Roe RH, Fisher Y, Eagle RC Jr, Fine HF, Cunningham ET Jr (2007) Oculoleptomeningeal amyloidosis in a patient with a TTR Val30Gly mutation in the transthyretin gene. Ophthalmology 114(11):e33-e37

26. Dowell JD, Fleck JD, Vakili ST, Benson MD (2007) Familial oculoleptomeningeal amyloidosis associated with primary angiitis of the CNS. Neurology 68(1):77-78

27. Petersen RB, Goren H, Cohen M, Richardson SL, Tresser N, Lynn A et al (1997) Transthyretin amyloidosis: a new mutation associated with dementia. Ann Neurol 41(3):307-313

28. Furuya H, Yoshioka K, Sasaki H, Sakaki Y, Nakazato M, Matsuo $\mathrm{H}$ et al (1987) Molecular analysis of a variant type of familial amyloidotic polyneuropathy showing cerebellar ataxia and pyramidal tract signs. J Clin Investig 80(6):1706-1711

29. Horowitz S, Thomas C, Gruener G, Nand S, Shea JF (1998) MR of leptomeningeal spinal and posterior fossa amyloid. AJNR Am J Neuroradiol 19(5):900-902

30. Taratuto AL (2010) BH, Salvatico R., Dogan A., Klein C., Dyck P.J. Leptomeningeal amyloidosis in an Argentinian patient of basque descent [Abstract]. J Neuropathol Exp Neurol 5:555

31. Charidimou A, Peeters A, Fox Z, Gregoire SM, Vandermeeren Y, Laloux P et al (2012) Spectrum of transient focal neurological episodes in cerebral amyloid angiopathy: multicentre magnetic resonance imaging cohort study and meta-analysis. Stroke J Cereb Cir 43(9):2324-2330

32. Ando Y, Terazaki H, Nakamura M, Ando E, Haraoka K, Yamashita $\mathrm{T}$ et al (2004) A different amyloid formation mechanism: de novo oculoleptomeningeal amyloid deposits after liver transplantation. Transplantation 77(3):345-349

33. Terazaki H, Ando Y, Nakamura M, Obayashi K, Misumi S, Shoji $S$ et al (2001) Variant transthyretin in blood circulation can transverse the blood-cerebrospinal barrier: qualitative analyses of transthyretin metabolism in sequential liver transplantation. Transplantation 72(2):296-299

34. Yamashita T, Ando Y, Ueda M, Nakamura M, Okamoto S, Zeledon ME et al (2008) Effect of liver transplantation on transthyretin Tyr114Cys-related cerebral amyloid angiopathy. Neurology 70(2):123-128

35. Sekijima Y, Wiseman RL, Matteson J, Hammarstrom P, Miller SR, Sawkar AR et al (2005) The biological and chemical basis for tissue-selective amyloid disease. Cell 121(1):73-85 